\title{
Redes, hierarquia e interdependência social nas relações de compadrio do século XVIII (Viamão, 1747-1769)
}

\author{
Networks, hierarchy and social interdependence in social relations of \\ compadrazgo in the XVIII century (Viamão, 1747-1769)
}

\author{
Israel Silva Aquino * \\ Universidade Federal do Rio Grande do Sul \\ israel.aquino@ufrgs.br \\ Fabio Kuhn ${ }^{* *}$ \\ Universidade Federal do Rio Grande do Sul \\ fabio.kuhn@ufrgs.br
}

\begin{abstract}
Resumo: Este artigo investiga a formação de redes de compadrio na freguesia de Viamão do século XVIII, buscando investigar como estas reproduziam as relações de diferenciação, hierarquia e interdependência constituídas por indivíduos de famílias abastadas da região. Conforme aponta João Fragoso, a sociedade constituída no Brasil do período colonial foi marcada por uma "hierarquia social costumeira", constituída por intrincadas relações entre indivíduos de diferentes estratos sociais. Assim, este artigo foi dividido em três partes: na primeira, apresentaremos o método adotado; a seguir, é realizada uma breve revisão a respeito dos estudos sobre o compadrio no Brasil. Finalmente, o mapeamento destas redes de 'compadres' foi realizado através da sistematização dos registros de batismo da região de Viamão, no período de 1747 a 1759, recorrendo-se às ferramentas conceituais da metodologia da Análise de Redes Sociais para fins de análise e crítica dos resultados.
\end{abstract}

Palavras-Chave: Hierarquias Sociais. Redes de Compadrio. Análise de Redes Sociais. Estratégias Sociais.

Abstract: This article investigates the formation of compadrazgo networks in the parish of Viamão in the 18th century. It focuses on how they reproduced dynamics of differentiation, hierarchy and interdependence constituted by individuals from families of the region. According to João Fragoso, the society constituted in Brazil from the colonial period was marked by a "customary social hierarchy", constituted by intricate relationships among individuals from different social strata. This article was divided in three parts: in the first, we will present the method adopted; next, is a brief review of studies on compadrazgo in Brazil. Finally, the mapping of these networks was carried out, through the systematization of baptismal records of the Viamão region from 1747 to 1759 , and using the tools of the Social Network Analysis methodology to perform the analysis of the results.

Keywords: Social Hierarchies. Compadrazgo Networks. Social Network Analysis. Social Strategies.

Recebido: 01 mar. 2018.

Aprovado: 12 abr. 2018.

\footnotetext{
* Mestrando pelo Programa de Pós-graduação em História da Universidade Federal do Rio Grande do Sul (UFRGS), instituição na qual obteve seu bacharelado em História. É membro do Corpo Editorial da Revista Aedos e do Grupo Pesquisa "SARAS - Sociedades de Antigo Regime no Atlântico Sul", CNPq.

** Professor associado I da UFRGS. Possui graduação e mestrado em História pela UFRGS e doutorado em História pela Universidade Federal Fluminense. Representante da UFRGS no comitê acadêmico "Historia, regiones y fronteras" da Asociación de Universidades del Grupo Montevideo.
} 
A ideia de rede social fomenta, entre os diferentes paradigmas e disciplinas pelos quais transita, uma multiplicidade de abordagens e compreensões, o que torna por vezes difícil sua conceituação. De forma bastante ampla, podemos tomar uma rede social enquanto um "conjunto finito de atores e a(s) relação(ões) que se estabelecem entre eles". ${ }^{1}$ A Análise de Redes Sociais (do inglês SNA - Social Network Analysis) consiste em um campo multidisciplinar que conjuga elementos da Sociologia Relacional, da Antropologia, da Psicologia Social e mesmo da Matemática (através da teoria dos grafos). Propõe, fundamentalmente, um estudo sistemático de redes representadas graficamente, tomadas enquanto representações das estruturas de relacionamento que pessoas ou organizações estabelecem entre si.

Com o avanço e disseminação do método de análise de redes entre os estudos históricos, cunha-se o termo Historical Network Research (HNR), um campo de estudos que aplica a análise de redes a estudos de séries documentais diversificadas, tais como correspondências, documentação notarial ou registros eclesiásticos, buscando problematizar as relações estabelecidas entre atores históricos e seus diversos vínculos - familiares, comerciais, institucionais, entre outros. Trabalhos nesse campo compartilham a compreensão de que métodos formais derivados da análise de redes podem ser proveitosamente aplicados também a corpos selecionados de registros históricos, oferecendo ao pesquisador novas possibilidades de análise e crítica de suas fontes, e rompendo assim com uma tendência anterior em estudos históricos de utilizar o conceito de rede de forma metafórica, sem o recurso efetivo ao instrumental proporcionado pela SNA. ${ }^{2}$

Este trabalho se propõe a estudar a formação de redes de compadrio na freguesia de Viamão no período colonial, buscando investigar sua utilização como estratégia de atuação e reprodução social por algumas famílias abastadas da região. Para tanto, utilizamos registros de batismo, a fim de promover o mapeamento de tais redes, além de se recorrer às ferramentas conceituais da metodologia da análise de redes para fins de interpretação e análise das mesmas.

O recorte estabelecido para o presente trabalho abrange o período de 1747 , data do primeiro registro de batismo da freguesia, até 1759 , data de encerramento do Livro I de batismos da Capela de Nossa Senhora de Conceição de Viamão, ${ }^{3}$ totalizando 559 registros

1 WASSERMAN, Stanley; FAUST, Katherine. Social Network Analysis: methods and applications. Cambridge: Cambridge University Press, 1994, p. 20.

2 São exemplos os estudos de Lemercier e Ponce Leiva e Amadori. Cf.: LEMERCIER, Claire. Formal network methods in history: Why and how? Social Networks, Political Institutions, and Rural Societies. Turnhout: Brepols Publishers, 2012, p. 281-297. Disponível em: <https://hal.inria.fr/file/index/docid/649316/filename/lemercier_A_zg.pdf>. Acesso em: 03 ago. 2017; PONCE LEIVA, Pilar; AMADORI, Arrigo. Redes sociales y ejercicio del poder en la América Hispana: consideraciones teóricas y propuestas de análisis. Revista Complutense de Historia de América, Madrid, v. 34, 2008, p. 15-42. Disponível em: <http://www.pucsp.br/cehal/downloads/relatorios/rev_complutense/redes_sociales_poder_hispanoameri ca.pdf >. Acesso em: 04 ago. 2017.

${ }^{3}$ NEUMANN, Eduardo; KUHN, Fábio. Resgate de fontes paroquiais - Porto Alegre e Viamão, século XVIII. $1^{\circ}$ Livro de Batismo de Viamão. Porto Alegre: [s.n.], 2009. 
analisados. A partir destas fontes, foram selecionados os registros que envolvem os integrantes de duas famílias da região, os Pinto Bandeira e os Ornellas de Menezes, a fim de mapear suas redes de apadrinhamento no período. A análise desses registros será complementada pela utilização dos Róis de Confessados da freguesia, ${ }^{4}$ referentes aos anos de 1751, 1756, 1757 e 1758, a partir dos quais pudemos ter acesso aos dados a respeito da população residente no período. A partir deste recorte, buscamos tecer algumas considerações iniciais a respeito da utilização da instituição do compadrio na região estudada.

\section{Análise de Redes Sociais e História}

De acordo com Bertrand, a noção de rede social remete a uma estrutura construída com base nas relações existentes entre indivíduos. ${ }^{5}$ Essa noção, por sua vez, remete a uma primeira caracterização da rede em termos morfológicos, onde essa estrutura pode assumir um formato egocentrado (construída em torno de um indivíduo) ou polinodal (que evidencia a existência de relações fragmentadas, organizadas em torno de um ou vários núcleos). Assim, conforme aponta Fioravante, o estudo desses vínculos busca evidenciar a capacidade de cada ator social manipular o conjunto de suas ligações com o intuito de satisfazer seus interesses e necessidades. $^{6}$

Partindo da teoria dos grafos e da sociometria, uma rede social é representada graficamente como um conjunto de pontos, representando os agente ou atores sociais, estes vinculados por uma série de relações, que são representadas pelas linhas do gráfico. Essas relações são influenciadas pelo posicionamento do indivíduo na rede (central ou periférico), seu acesso a recursos, a intensidade dos relacionamentos, a densidade da rede, entre outros. ${ }^{7}$

A primeira etapa da análise de redes é a criação do que chamamos matriz de adjacência, em que linhas e colunas representam os atores sociais envolvidos em determinada relação e contexto históricos. ${ }^{8}$ A elaboração das matrizes e seus grafos correspondentes é parte fundamental deste método. ${ }^{9}$ Cada matriz e seu grafo correspondem a uma espécie de instantâneo dos relacionamentos do grupo em análise. O grafo é formado pelas unidades de análise (pessoas, organizações) e pelas relações estabelecidas entre elas, que são

\footnotetext{
${ }^{4}$ Arquivo Histórico Da Cúria Metropolitana De Porto Alegre (AHCMPA). Róis de Confessados - Freguesia de Nossa Senhora da Conceição de Viamão - Anos de 1751, 1756, 1757 e 1758.

${ }^{5}$ BERTRAND, Michel. De la familia a la red de sociabilidad. Escuela de Historia, Rosário, ano 4, n. 6, 2012. Disponível em: <http://revistapaginas.unr.edu.ar/index.php/RevPaginas/article/view/94/94>. Acesso em: 02 ago. 2017, p. 61.

6 FIORAVANTE, Fernanda. Considerações acerca da Análise de Rede Social nas sociedades de Antigo Regime. Revista de Teoria da História, Goiânia, v. 10, n. 2, 2013, p. 221-240. Disponível em <https://www.revistas.ufg.br/teoria/article/view/29094/16186>. Acesso em: 03 ago. 2017, p. 222.

7 PONCE LEIVA, Pilar; AMADORI, Arrigo. Redes sociales y... Op. cit., p. 22.

8 PANDOLFI, Fernanda C.; BUENO, Newton P. Análise de redes sociais em História: noções básicas e sugestões de aplicação. Anais do XVIII Encontro Regional de História ANPUH-MG, 2014, Juiz de Fora. Disponível em: <http://www.encontro2014.mg.anpuh.org/resources/anais/34/1401385226_ARQUIVO_anpuhpaper2905corrigido.pdf>. Acesso em: 03 ago. 2017.

9 "Grafo" é o termo utilizado na SNA para designar a representação gráfica das redes.
} 
representadas por pontos (nódulos) e linhas, respectivamente. Pode também contar com setas, que indicam o sentido das ligações (relações) estabelecidas, mas estas podem ser omitidas, quando o grafo estiver representando relações multidirecionais.

De acordo com o tipo de grafo utilizado, as formas e cores dos nódulos variam, o que também ocorre com o comprimento das linhas, de forma a dar um significado visual ao que foi expresso na matriz pelo pesquisador. Para a elaboração destes grafos existem diversos softwares, disponíveis, de forma gratuita, na Internet, ou no mercado. São exemplos o Cyram, o Pajek e o NodeXL, ${ }^{10}$ este último um complemento da empresa Microsoft disponibilizado gratuitamente para o software Office Excel, que foi adotado para a elaboração das matrizes e componentes visuais deste trabalho.

Para além da elaboração das matrizes e a geração dos respectivos grafos, outra contribuição fundamental deste método é a produção dos coeficientes ou estatísticas de análise, denominadas métricas, que permitem evidenciar algumas das características dessas redes, colocando em evidência alguns tipos de relação que se estabelecem, ou destacando a atuação de um determinado agente no grupo a partir da posição por este assumida. Essas métricas cumprem papel fundamental para a análise, tanto quanto o recurso gráfico proporcionado pelo software.

Como exemplos, podemos citar o grau de centralidade (ou DeGree), que mede quantidade de nós (agentes) interligados a um nó determinado, demonstrando assim a atividade do nó no grafo. Esta é uma métrica direta, que indica a atividade de cada agente da rede e suas relações. Já o grau de intermediação, ou betweenes, mede a importância do nó ou agente na rede, no sentido de demonstrar quantas relações seriam 'quebradas' caso este se retirasse da rede. ${ }^{11}$ Retomaremos a discussão sobre cada uma das métricas, à medida que desenvolvemos a análise das redes mapeadas nas seções seguintes.

Uma das preocupações que surgem com o uso da SNA é a aparente simplificação das relações que se estabelecem ou, conforme aponta Thiago Gil, certa pretensão de objetivizar as relações humanas. Torna-se, portanto, necessário ressaltar que com esta técnica não se pretende dar conta da totalidade das relações, mas sim "apresentá-las de uma forma ordenada e visualmente inteligível para o investigador". ${ }^{12}$ Conforme aponta Hanneman:

Uma razão para a utilização das técnicas matemáticas e dos grafos na análise de redes sociais é que permite representar a descrição de uma rede de maneira concisa e sistemática. Também possibilita o uso de computadores para armazenar e manipular rapidamente a informação, de maneira mais precisa do que se fosse feito manualmente. [...] As representações formais asseguram que

10 o Cyram (Disponível em: <http://www.cyram.com/>) e o Pajek (Disponível em: <http://mrvar.fdv.uni-lj.si/pajek/>) são dois exemplos de softwares de análise de redes que dependem de licenciamento. Por outro lado, o complemento NodeXL (Disponível em: https://nodexl.codeplex.com/) e programas como o Gephi (Disponível em: <https://gephi.org/>) são exemplos de softwares disponibilizados de forma parcial ou totalmente gratuita, na internet.

${ }^{11}$ WASSERMAN, Stanley; FAUST, Katherine. Social Network Analysis... Op. cit., p. 77-83.

$12 \mathrm{GIL}$, Tiago Luís. O bando de Rafael Pinto Bandeira em uma representação gráfica: uma tentativa de aplicação da social network analysis na história social. Anais do I Colóquio do LAHES. Juiz de Fora, 2005, p. 1. Disponível em: <http://www.ufjf.br/lahes/files/2010/03/c1-a66.pdf>. Acesso em: 03 ago. 2017. 
toda a informação necessária se encontra representada sistematicamente e fornecem as regras para fazê-lo de forma eficiente. ${ }^{13}$

Faz-se necessário, desta forma, refletir sobre a utilização do instrumental proporcionado pela SNA em estudos históricos, e de forma particular na aplicação desta para a análise de fontes do período colonial. A esse respeito, Michel Bertrand nos lembra do cuidado que se faz necessário ao empregar em estudos históricos ferramentas que foram construídas para pensar sociedades contemporâneas:

Não podemos, pois, descartar o impacto que pode ter esta transferência de um modelo de relação social elaborado para a análise de um dado tipo de sociedade para sociedades de Antigo Regime, cujas regras de funcionamento eram radicalmente diferentes. [...] A utilização de métodos de pesquisa baseados em fontes não permite uma abordagem ou apreensão global do objeto de estudo, colocando o historiador em uma posição muito diferente daquela que goza o sociólogo ou o antropólogo. ${ }^{14}$

Deste modo, aponta Bertrand, existem pelo menos duas limitações a que precisamos estar atentos ao adotar a SNA para o estudo de sociedades de Antigo Regime, a saber: por um lado, estamos limitados pelas próprias fontes, e pela forma como nelas se apresenta nosso objeto. Bertrand nos lembra que "uma rede não pode existir, em absoluto, fora [...] de uma finalidade ou de um projeto em particular [...], construído por atores sociais em um contexto específico". ${ }^{15}$ Em outras palavras, entende-se que a própria identificação dessas redes em uma fonte histórica é precedida pela atuação dos agentes históricos em prol de seus objetivos ou projetos próprios. Ficando apenas no exemplo que exploramos neste trabalho, caberia perguntar: que projeto mobilizava os atores que se envolveram nas redes de compadrio identificadas? Em que contexto estavam inseridos, e porque realizaram determinadas escolhas?

Por outro lado, Bertrand aponta que as redes a que temos acesso através das fontes serão sempre e necessariamente limitadas, seja pelo recorte temporal, espacial, ou pela própria dinâmica que governava as relações estabelecidas entre os agentes (ou, mais precisamente, as mudanças nessas relações). Desta forma, podemos dizer que o que chega ao historiador são, na verdade, 'fragmentos' de rede, de modo que "a reconstituição [dessas] redes se limita [...] essencialmente a uma aproximação sincrônica, em detrimento [...] da diacronia". ${ }^{16}$ Bertrand reforça, nesse sentido, a necessidade de que o historiador adote duas precauções:

Ao querer empurrar os limites de uma rede o mais longe possível em um espaço social dado para reconstruir sua globalidade [...], corre-se o risco, sobretudo, de se chegar em uma verdadeira "apoplexia do conceito" [...] [onde] "todo mundo está em relação com todo mundo". Também parece mais pertinente [...] interessar-se na lógica combinatória que relações e vínculos permitem

\footnotetext{
13 HANNEMAN, Robert A. Introducción a los métodos del Análises de Redes Sociales. Revista Redes, Barcelona, Universidad Autonoma de Barcelona, 1-26, 2000, p. 1 Disponível em: <http://revistaredes.rediris.es/webredes/text.htm>. Acesso em 18 abr. 2016.

${ }^{14}$ BERTRAND, Michel. De la familia a la... Op. cit., p. 57.

${ }^{15}$ Idem.

${ }^{16}$ Ibidem, p. 58.
} 
estabelecer entre os atores no marco de uma rede, mais que no simples fenômeno acumulativo [de relacionar os vínculos]. ${ }^{17}$

Cabe, portanto, ao pesquisador interessado em aplicar o método apresentado, o cuidado e o esforço, conforme lembra o próprio Bertrand, de demonstrar efetivamente as consequências das relações identificadas, mais que o simples ato de enumerá-las. Retomamos parte desta discussão ao longo deste trabalho, ao propor um breve exercício de análise das redes de compadrio de algumas famílias viamonenses do século XVIII. Antes, porém, cabe apresentar algumas considerações a respeito do marco teórico que embasará estas análises, especificamente no tocante a forma como se desenhavam as hierarquias sociais e os modos de sociabilidade no período colonial.

\section{Compadrio e hierarquias sociais no Brasil setecentista}

Donald Ramos, ao analisar o sistema de compadrio na região de Vila Rica (MG), atenta para dois aspectos. O primeiro diz respeito ao destaque dado ao tema na literatura hispanoamericana, enquanto a literatura especializada em português sobre o tema à época era ainda escassa. A seguir, Ramos apresenta as duas correntes que discutem os aspectos espirituais e sociais envolvidos no batismo e suas relações subjacentes, como o próprio compadrio. ${ }^{18}$

A primeira destas correntes, fundada em uma interpretação antropológica estruturalista, oferece uma visão do batismo como um ritual de renascimento, onde "o nascimento biológico, dominado pela mulher, é o resultado de um processo impuro que seria substituído por um nascimento ritualizado e puro em que pais novos são escolhidos". ${ }^{19}$ Nesse contexto, o processo do batismo é compreendido pela sua função espiritual. O compadrio, nesta perspectiva, é entendido como uma instituição de parentesco ritual, assimétrica, que envolve relações de dom e contra-dom e estende às relações familiares dos envolvidos para o plano espiritual, metafísico. ${ }^{20}$

A segunda perspectiva teórica que aborda estas relações adota uma interpretação funcionalista, compreendendo o batismo e a escolha dos padrinhos como "uma maneira de construir laços sociais que funcionavam para integrar a comunidade em termos, ao mesmo tempo, horizontal e vertical". ${ }^{21}$ Esta é a interpretação mais comum e que tem sido mais frequentemente adotada nos trabalhos recentes a respeito do compadrio, seja para a

\footnotetext{
${ }^{17}$ BERTRAND, Michel. De la familia a la... Op. cit., p. 64.

18 RAMOS, Donald. Teias sagradas e profanas: o lugar do batismo e compadrio na sociedade de Vila Rica durante o século do ouro. Varia Historia, Belo Horizonte: UFMG, n. 31, 41-68, jan. 2004, p. 51-52. Disponível em: <https://goo.gl/3X9UZi>. Acesso em 22 jan. 2018.

${ }^{19}$ Idem.

20 O termo "economia do dom", cunhado pelo francês Marcel Mauss em 1923, é usado para definir ações sociais de um indivíduo que tem uma contrapartida indireta. A concepção da dádiva, conforme Mauss, está estruturada de forma tripartida, abrangendo não apenas o ato da doação, mas também a recepção e a restituição pelo beneficiado. Cf.: MAUSS, Marcel. Essai sur le don forme et raison de l'échange dans les sociétés archaïques. L'Année sociologique, v. 1, 1923. p. 30-186.

${ }^{21}$ RAMOS, Donald. Teias sagradas e... Op. cit., p. 51.
} 
população livre ou cativa; todavia, estamos mais inclinados a concordar com a leitura proposta por Ramos, ao compreender estas mais como visões complementares do que necessariamente opostas. Assim, entende-se que a mesma instituição - o compadrio -, compreendida enquanto relação social e espiritual firmada entre os pais biológicos e espirituais de uma criança através de um ritual de batismo (no caso, o católico), poderia cumprir funções tanto sociais como espirituais de maneira simultânea, especialmente quando levamos em conta as estruturas que coexistiam na sociedade em análise: o patriarcalismo, o clientelismo e a catolicismo como crença ainda muito arraigada.

Surge, portanto, outro conceito importante para o esforço de compreensão a que nos propomos, que se refere ao construto de estratégia, cuja origem encontra-se nas teorias antropológicas. Também este terá uma abordagem distinta, a partir do paradigma que se adota para sua leitura. Pierre Bourdieu, na década de 1970, propõe, a partir de uma leitura estruturalista, uma noção de estratégia como instrumento de ruptura com um ponto de vista objetivista e com a ação do agente, fundamentalmente ligada ao conceito de habitus, também central em sua obra.

falar de estratégias de reprodução não é atribuir ao cálculo racional, ou mesmo à intenção estratégica, as práticas através das quais se afirma a tendência dos dominantes, dentro de si mesmos, de perseverar. É lembrar somente que o número de práticas fenomenalmente muito diferentes organizam-se objetivamente, sem ter sido explicitamente concebidas e postas com relação a este fim [...]. Isto porque essas ações têm por princípio o habitus, que tende a reproduzir as condições de sua própria produção, gerando, nos domínios mais diferentes da prática, as estratégias objetivamente coerentes e as características sistemáticas de um modo de reprodução. ${ }^{22}$

Por sua vez, Fredrik Barth, em um texto anterior e de viés funcionalista, entende a estratégia como um conjunto de "ações planejadas, das decisões e das escolhas individuais", considerando, assim, preferível realizar a análise da organização social em vez da estrutura social - tomando como central, todavia, o conjunto de uma infinidade de ações individuais como formadora desta organização. ${ }^{23}$ Portanto, como se vê, no centro do debate entre as duas correntes está a atuação subjetiva, a importância que cumpria ao indivíduo e sua atuação racional, por um lado, frente a uma atuação diluída e até mesmo inconsciente, tomada assim como habitus, por outro.

Seja para a comunidade livre ou escrava, a prática do compadrio cumpria o papel importante de criar ou reforçar laços sociais, perspectiva que é reforçada por diversos estudos. $^{24}$ Ramos aponta uma dupla estratégia observada na escolha de padrinhos e

22 BOURDIEU, Pierre. La noblesse d'État. Grandes écoles et esprit de corps. Paris: Les Éditions de Minuit, 1989, p. 386-387.

${ }^{23}$ BARTH, Fredrik. Models of Social Organization. London: Royal Anthropological Institute, 1966, p. 4.

${ }^{24}$ A título de exemplo, citamos os trabalhos utilizados nesta análise: RAMOS, Donald. Teias sagradas e... Op. cit.; VENÂNCIO, Renato; SOUSA, Maria José; PEREIRA, Maria Teresa. O Compadre Governador: redes de compadrio em Vila Rica de fins do século XVIII. Revista Brasileira de História, São Paulo, v. 26, n. 52, 273-294, 2006. Disponível em: <http://www.scielo.br/scielo.php?script=sci_arttext\&pid=S010201882006000200012 >. Acesso em: 03 ago. 2017; KUHN, Fabio. Gente da Fronteira: família, sociedade e poder no sul da América Portuguesa - Século XVIII. 2006. Tese (Doutorado em História). Programa de Pós-graduação em História da Universidade Federal Fluminense, Niterói. Disponível em: 
madrinhas para a região de Vila Rica (MG) no século XVIII. A escolha dos compadres normalmente recaía sobre homens de status semelhante ou superior, demonstrando uma estratégia de criação de vínculos com iguais que buscava estender os laços sociais. As madrinhas, por outro lado, eram comumente escolhidas entre mulheres da família, em movimento projetado de modo a reforçar laços familiares; a escolha dos padrinhos cumpria, assim, uma função dupla, de criar novos laços e reforçar relações existentes, gerando uma imagem de vários de teias sociais superpostas. ${ }^{25}$ Outros estudos, como os de Hameister, Brugger e Marques chegaram a conclusões semelhantes. ${ }^{26}$

Mas o estabelecimento de relações entre "compadres", "comadres" e afilhados não deve ser visto, é importante que se diga, como sinônimo de uma rede de 'iguais', ainda que os envolvidos tivessem status social, por vezes, semelhantes. De acordo com Venâncio et. al., em um contexto de elevada hierarquia social, o compadrio tornava-se mais um elemento legitimador das relações de poder internas ou externas aos grupos sociais, surgindo assim as noções de "amizade desigual" e "intermediários sociais", servindo as redes de compadrio como base para o estabelecimento de complexas teias de favorecimento e fidelidade:

na sociedade da época, a noção de 'prestígio' vinculava-se à capacidade de dispor de recursos [...], gerando assim uma 'economia de favores', de dom e contra-dom; em outras palavras, de reciprocidade social envolvendo desiguais. Ao benfeitor cabia conceder e ao beneficiado cabia ser fiel, não sendo esse gesto visto como um desvio da 'norma', mas sim como sua corporificação. ${ }^{27}$

Esta questão também foi apontada por Sílvia Brügger, que indicou o esforço pela realização de alianças verticais, ou alianças "para cima", onde os pais buscavam como padrinhos sujeitos de hierarquia social superior ou semelhante, como estratégia social para obtenção de benefícios, prestígio ou segurança. ${ }^{28}$ Assim, pais cativos ou forros apareciam nos livros de batismo pesquisados pela autora muito mais frequentemente estabelecendo relações de compadrio com cidadãos livres, enquanto nas famílias livres as associações se estabeleciam

\footnotetext{
<http://www.historia.uff.br/stricto/teses/Tese-2006_KUHN_Fabio-S.pdf>. Acesso em: 03 ago. 2017; HAMEISTER, Martha D. Para dar calor à nova povoação: estudo sobre estratégias sociais e familiares a partir dos registros batismais da vila do Rio Grande (1738-1763). 2006. Tese (Doutorado em História Social). Programa de Pós-graduação em História Social da Universidade Federal do Rio de Janeiro, Rio de Janeiro. Disponível em: <http://www.dominiopublico.gov.br/pesquisa/DetalheObraForm.do?select_action=\&co_obra $=107310>$. Acesso em: 03 ago. 2017; BRUGGER, Silvia M. J. Minas Patriarcal: família e sociedade, São João del Rei, Séculos XVIII e XIX. São Paulo: Annablume, 2007; FARINATTI, Luís A. E.; VARGAS, Jonas Moreira. Elites regionais, guerra e compadrio: a família Ribeiro de Almeida e suas redes de relações (Rio Grande do Sul, c. 1816 - c. 1844). Topoi, Rio de Janeiro, v. 15, n. 29, 389-413, 2014. Disponível em: <http://dx.doi.org/10.1590/2237-101X015029001>. Acesso em: 03 ago. 2017.

${ }^{25}$ RAMOS, Donald. Teias sagradas e... Op. cit., p. 59.

26 HAMEISTER, Martha D. Para dar calor à... Op. cit.; BRUGGER, Silvia M. J. Minas Patriarcal... Op. cit.; MARQUES, Rachel dos S. Por cima da carne seca: hierarquia e estratégias sociais no Rio Grande do Sul (c. 1750-1820). 2011. Dissertação (Metrado em História). Programa de Pós-graduação em História da Universidade Federal do Paraná, Curitiba. Disponível em: <http://www.humanas.ufpr.br/portal/arquivos/Rachel.pdf>. Acesso em: 6 ago. 2017.

27 VENÂNCIO, Renato; SOUSA, Maria José; PEREIRA, Maria Teresa. O Compadre Governador... Op, cit., p. 274.

${ }^{28}$ BRUGGeR, Silvia M. J. Minas Patriarcal... Op. cit., p. 285.
} 
preferencialmente com outras famílias livres, de estrato social e econômico semelhante ou superior. ${ }^{29}$

Essa afirmação precisa ser entendida em seu contexto mais amplo, qual seja, o contexto de hierarquização social das sociedades de Antigo Regime. Ao pensar a instituição do compadrio para esta freguesia sul-brasileira do século XVIII, é preciso compreender a dinâmica social na qual esta sociedade estava inserida e que governava esta e outras relações. Conforme aponta Giovani Levi, as sociedades de Antigo Regime eram governadas pela "justiça distributiva", isto é, "por uma justiça que aspira a garantir a cada um o que lhe corresponde segundo seu status social". ${ }^{30}$ Neste contexto, as relações engendradas pelos atores sociais estavam atravessadas pela ideia de equidade, que aqui deve ser entendida como fundamentalmente distinta do conceito contemporâneo de igualdade: em um corpo social que baseava sua relações em uma estratificação rígida e costumeira, a equidade social cimentava a noção de uma sociedade de desiguais, onde a atuação de seus membros estava pautada pela busca de distinções e privilégios. ${ }^{31}$

Nessas circunstâncias, é possível pensar o compadrio como parte de uma estratégia de atuação que buscava favorecer a posição de um indivíduo ou grupo frente a seus semelhantes, atuação esta que era permanentemente pensada como um exercício de diferenciação social. Tal pode ser percebido nas fontes que chegaram até nós, onde parte deste esforço foi reproduzido. João Fragoso traz um exemplo disto em fontes paroquiais do Rio de Janeiro no século XVIII:

Através do estudo das freguesias rurais do Rio de Janeiro é possível recuperar aspectos de tal hierarquia nas categorias usadas pelos clérigos das freguesias para classificar seus paroquianos. Eles recorriam, entre outros procedimentos, a patentes de ordenanças, a títulos de dona, a qualitativos jurídicos como forro, a qualitativos sociais como pardos ou ainda a expressões como "assistente de casa". 32

Para os registros de Viamão identificamos idêntico expediente, tendo os clérigos da região tomado o cuidado de indicar distintivos tais como patentes militares e religiosas, condições sociais tais como escravo, forro ou administrado, local de origem (no caso de migrantes), bem como o distintivo 'dona' para as esposas e filhas de potentados locais.

Esse cuidado por parte dos párocos não acontecia por acaso. João Fragoso aponta como a organização da sociedade e da res publica durante o período da conquista esteve

\footnotetext{
${ }^{29}$ BRUGGER, Silvia M. J. Minas Patriarcal... Op. cit., p. 286-292.

30 LEVI, G. Reciprocidade Mediterrânea. In: RIBEIRO, M.; ALMEIDA, C. M. C. de (orgs.). Exercícios de Micro-história. Rio de Janeiro: FGV, 2009, p. 51-86.

31 Giovani Levi propõe pensar conceitos como reciprocidade, equidade e justiça distributiva para sociedades que se desenvolveram no contexto do Antigo Regime mediterrâneo. Contudo, estamos inclinados a concordar com o que propõe autores como João Fragoso e Manuel Hespanha, ao pensar estes como extensíveis às sociedades que se desenvolveram no Atlântico Sul, na medida em que estas últimas buscavam mimetizar algumas das práticas que imprimem significado ao conceito de Antigo Regime, em especial a hierarquização que atravessava as relações presentes nessas sociedades.

32 FRAGOSO, João. Capitão Manuel Pimenta Sampaio, senhor do Engenho do Rio Grande, neto de conquistadores e compadre de João Soares, pardo: notas sobre uma hierarquia social costumeira (Rio de Janeiro, 1700-1760). In: FRAGOSO, João; GOUVÊA, Maria de Fátima. Na Trama das Redes: política e negócios no império português, séculos XVI-XVIII. São Paulo: Civilização Brasileira, 2010, p. $245-294$.
} 
profundamente marcada por práticas costumeiras, construídas pelas regularidades das sociabilidades locais, e por uma concepção corporativa, advinda de uma orientação valorativa calcada em elementos do Velho Mundo. A materialidade dessas práticas, por sua vez, teria se dado na forma de relações de clientela e de parentesco consanguíneo e fictício, forjando um idioma de relações de dependência que atravessava toda aquela sociedade. ${ }^{33}$

Ao transportar esses elementos para a problemática específica de que tratamos aqui, ou seja, a formação das redes de compadrio (e neste caso, para o compadrio de livres, mas não só), entendemos ser possível identificar de forma clara esse conjunto de elementos nas estratégias adotadas pelos atores envolvidos. A partir destes, portanto, buscamos na próxima seção pensar de que forma as redes de compadrio podem nos ajudar a evidenciar e refletir sobre essas formas de sociabilização e sobre o modo como as hierarquias sociais atravessavam as relações presentes na sociedade estudada.

\section{Análise de redes de compadrio em Viamão}

O 10 livro de batismos da freguesia de Viamão reúne 559 registros de batismo, realizados entre os anos de 1747 e 1759. Neste período, conforme podemos depreender dos róis de confessados ainda disponíveis, a freguesia manteve uma população regular de cerca de 1000 a 1200 pessoas. ${ }^{34}$ Deste conjunto, o recorte estabelecido para este trabalho propõe a análise das redes de compadrio formadas por duas famílias proprietárias de terras na região, que compareceram à pia batismal 70 vezes, sendo 44 batismos envolvendo a família Ornelas de Menezes e 26 envolvendo a família Pinto Bandeira.

A família Pinto Bandeira constituiu-se em um importante grupo de poder na capitania de São Pedro do Rio Grande do Sul durante o século XVIII. Originária de Laguna, teve entre seus membros militares de carreira, estancieiros e, mais tarde, um governador da capitania, Rafael Pinto Bandeira, que à época dos registros levantados para este estudo estava entrando na adolescência. Francisco Pinto Bandeira, o patriarca da família, era descendente de importante família lagunense, sendo neto do capitão-mor da vila, Francisco de Brito Peixoto, cujos esforços na 'conquista' do Continente de São Pedro foram decisivos para a ocupação da região de Viamão. ${ }^{35}$ Fixado em Viamão pelo menos desde a década de 1730 , Francisco obteve a concessão de duas sesmarias na região através de despacho exarado pelo governador Gomes Freire, no ano de $1752,{ }^{36}$ fixando sua sede na região da Guarda, situada na margem superior do rio Gravataí, onde atuou como comandante da mesma Guarda.

Esta região concentrava o maior contingente populacional da Freguesia, conforme demonstram os róis da década de 1750, e era onde estava localizado o Registro, local onde

\footnotetext{
33 FRAGOSO, João. Capitão Manuel Pimenta... Op. cit., p. 248-249.

34 Considerando livres e cativos adultos, e projetando o número de crianças.

35 KUHN, Fabio. Gente da Fronteira... Op. cit., p. 208.

${ }^{36}$ Registro de hua Carta de Sesmaria a Francisco Pinto Bandeira morador em Viamão. Rio Grande de São Pedro, 29 de maio de 1752. Revista do Arquivo Público Mineiro, Belo Horizonte, APM, v. $28,1928$.
} 
ocorria a cobrança dos tributos, especialmente sobre o gado em pé, que era levado pelos condutores de tropas às capitanias do Sudeste. ${ }^{37}$ Ponto de passagem praticamente obrigatório para quem entrava ou saía dos Campos, a Guarda foi instalada em 1737, tendo sido transformada em Registro em outubro de 1752, mesmo ano em que Francisco obteve a concessão de sua sesmaria.

Além de participar do povoamento inicial dos campos viamonenses, essa família se uniria, através do matrimônio, a outras famílias proprietárias que aportaram em Viamão, através de engenhosas estratégias sociais típicas de sociedade de Antigo Regime, criando um grupo com importante relevância política e econômica na freguesia em formação. Uma dessas famílias foi a do sesmeiro Antônio de Souza Fernando, cuja política de matrimônios deu origem a algumas das mais ilustres famílias do continente. Conforme aponta Kuhn, "os genros de Souza Fernando todos perfilam como membros do seleto grupo da elite local, donos de estâncias, gado e escravos", ${ }^{38}$ sendo um destes justamente o capitão Francisco de Pinto Bandeira, casado com a filha de Antônio, dona Clara Maria de Oliveira.

No período analisado neste trabalho, 13 integrantes da família são citados nos registros de batismo da freguesia de Viamão. Sete deles apadrinharam um total de 14 crianças, de diferentes estratos sociais; por outro lado, os irmãos Pinto Bandeira tiveram 11 filhos nesse mesmo período, sendo que pelo menos 8 destes foram apadrinhados por outros potentados proprietários de terra da região, ${ }^{39}$ demonstrando que a família estava fortemente relacionada dentro de seu estrato social. Ao todo, a família constituiu relações de compadrio com outros 41 homens e mulheres adultos, agregando em sua rede, para além de outros estancieiros, também indígenas, escravos, forros e migrantes açorianos. A seguir, o Grafo 1 representa a rede de apadrinhamentos formada por estas pessoas:

\footnotetext{
${ }^{37}$ KUHN, Fabio. Gente da Fronteira... Op. cit., p. 113.

38 Ibidem, p. 107.

${ }^{39}$ Os outros três batismos se deram dentro da família.
} 
Grafo 1: Rede de compadrio da Família Pinto Bandeira, 1747-1759

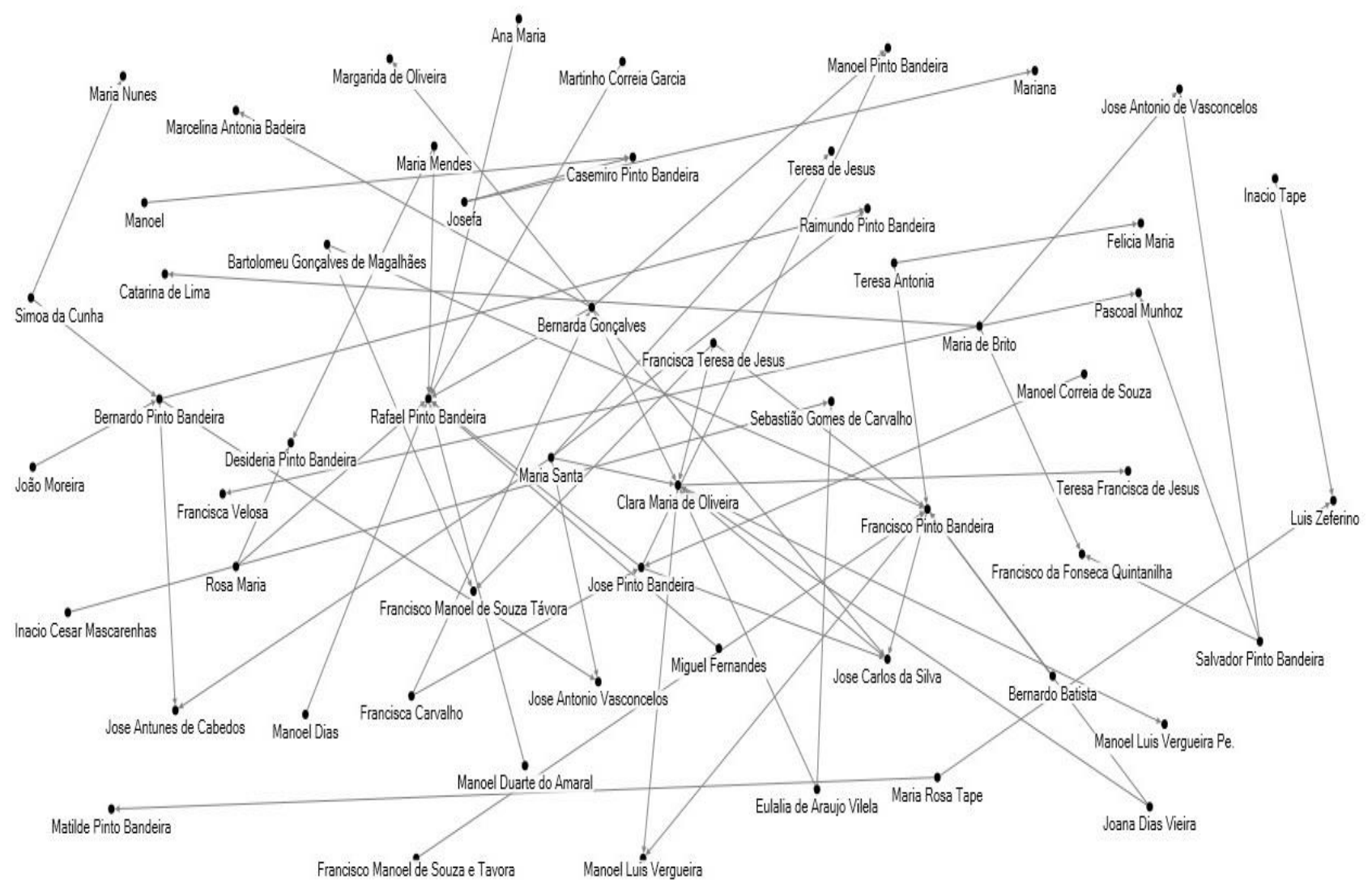

Fonte: Livro $1^{\circ}$ de Batismos de Viamão - 1747-1759.

Partindo desta imagem, é possível destacar que as relações deste grupo se concentram com maior intensidade ao redor de alguns dos agentes da rede. Entre eles, podemos apontar os nomes dos irmãos Francisco, Bernardo e José Pinto Bandeira, bem como suas esposas, Clara Maria, Maria Santa e Bernarda, respectivamente. Destaca-se também o nome de Rafael Pinto Bandeira, que no período entre seus 11 e 13 anos já havia apadrinhado 6 crianças, formando vínculos com 9 'compadres' e 'comadres', sendo 8 destes externos à família.

Avançando na análise destas relações, reproduzimos a seguir a Tabela 1 , que reúne algumas métricas produzidas a partir dos Pinto Bandeira para os sete agentes acima mencionados: 
Tabela 1: Métricas da rede de compadrio da família Pinto Bandeira

\begin{tabular}{|l|c|c|c|c|}
\hline & Centralidade & $\begin{array}{c}\text { Coeficiente de } \\
\text { Intermediação }\end{array}$ & $\begin{array}{c}\text { Grau de } \\
\text { Proximidade }\end{array}$ & $\begin{array}{c}\text { Grau de } \\
\text { Relevância }\end{array}$ \\
\hline Bernarda Gonçalves & 7 & 672,00 & 0,010 & 2,489 \\
\hline Bernardo Pinto Bandeira & 5 & 235,00 & 0,005 & 2,021 \\
\hline Clara Maria de Oliveira & 9 & 987,33 & 0,010 & 3,152 \\
\hline Francisco Pinto Bandeira & 8 & 387,67 & 0,008 & 2,901 \\
\hline Maria Santa & 5 & 545,00 & 0,008 & 1,885 \\
\hline José Pinto Bandeira & 5 & 176,00 & 0,008 & 1,812 \\
\hline Rafael Pinto Bandeira & 9 & 582,00 & 0,008 & 3,557 \\
\hline
\end{tabular}

Fonte: Livro $1^{\circ}$ de Batismos de Viamão, 1747-1759.

Conforme mencionamos na seção 2, a produção dos coeficientes de análise é parte fundamental da SNA. Para a rede apresentada aqui, esta afirmação é especialmente verdadeira: se a imagem do Grafo 1 pode dar a impressão de que os relacionamentos deste grupo eram bastante dispersos, a análise destas métricas, especialmente para os agentes destacados, permite visualizar com mais clareza o papel de cada ator nas relações estabelecidas neste grupo.

Inicialmente, podemos destacar o papel que as mulheres da família - Clara, Maria Santa e Bernarda - cumpriam. Observando a segunda coluna da tabela, que informa o grau de centralidade de cada agente, podemos observar que estas três mulheres formaram vínculos com 21 pessoas ao longo do período estudado, sendo que 10 destes relacionamentos corresponderam a vínculos de compadrio com proprietários rurais da região ou suas esposas. O grau de centralidade é definido como o número de ligações incidentes em um vértice em particular. ${ }^{40}$ Considerando as informações de que dispomos, esse dado nos permite apontar que essas mulheres cumpriram papel importante no estabelecimento das relações horizontais da família, ligando suas casas à de outras famílias da elite sul-rio-grandense através do parentesco espiritual.

Exemplo disso, Clara Maria de Oliveira, a esposa do chefe do grupo Pinto Bandeira na época, Francisco, é a pessoa que apresenta o maior grau de centralidade e intermediação nesta rede. O grau de intermediação, conforme já apontamos, é uma métrica importante, por indicar as relações que seriam 'quebradas' com a retirada do agente da rede. Assim, Clara aparece neste instantâneo dos relacionamentos de sua família cumprindo uma das funções mais importantes para a Teoria de Redes, que se refere ao conceito de intermediário, ${ }^{41}$ ou

\footnotetext{
40 WASSERMAN, Stanley; FAUST, Katherine. Social Network Analysis... Op. cit., p. 100.

41 Também referido na bibliografia como conector, gozne ou broker.
} 
seja, pessoas que atuam como conectores entre diferentes grupos, ou que constantemente são procuradas por outras pessoas para obtenção de favores ou de acesso a outros agentes da rede. $^{42}$

Para entender o que essa métrica nos informa a respeito da atuação de dona Clara Maria nas relações de sua família, analisemos brevemente os registros de batismo onde seu nome é mencionado. Entre 1747 e 1759, o casal Francisco e Clara teve dois filhos, Evaristo e Felizberto. Ambos tiveram como padrinhos religiosos, no caso os padres Manoel Luís Vergueira e José Carlos da Silva, este último também um sesmeiro da região. ${ }^{43}$ Evaristo foi consagrado à Nossa Senhora da Conceição, que aparece como sua madrinha (o registro não cita o motivo para tal), e Felizberto teve como madrinha Francisca Teresa de Jesus, esposa de Bartolomeu Gonçalves de Magalhães. Já entre os afilhados de Clara Maria, temos dois sobrinhos (filhos dos cunhados Bernardo e José), além de dois filhos do mesmo Bartolomeu Magalhães e um filho de Inácio César de Mascarenhas. Estes dois homens são mencionados nas fontes como proprietários de terras na região do rio Caí e fundadores do povoado que deu origem ao que hoje é o município de Montenegro, no RS. A lista de afilhados é concluída pela pequena Gertrudes, filha do casal de açorianos Bernardo e Joana.

Essa diversidade nas relações mantidas por dona Clara Maria é justamente o que justifica a diferenciação nos índices que the são correspondentes nesta rede e nos sugere a importância de sua atuação para a família à qual pertencia. Suas relações abrangiam tanto o fortalecimento das relações intrafamiliares quanto a manutenção de relações horizontais com famílias de estrato social semelhante. Porém, através do apadrinhamento de uma filha de migrantes, Clara atua (junto a seu marido, neste caso) também no sentido de estabelecer uma relação social vertical, que possivelmente esteve relacionada ao desenvolvimento de uma relação de clientela entre aqueles casais.

Importante notar, ainda, que Clara Maria não apenas era esposa de um estancieiro com cargo militar e comandante do registro da Guarda de Viamão, mas também filha de um grande proprietário de terras, Antônio de Souza Fernando, chefe de uma importante família originária da Colônia do Sacramento, cujas filhas - irmãs de Clara - casaram-se todas com estancieiros e potentados no Rio Grande. Dona Clara, como aparece nos registros, fazia jus, portanto, a esse epíteto característico, muito utilizado nos registros paroquiais para distinguir as mulheres pertencentes a boas famílias.

Por outro lado, Rafael, filho de Francisco e Clara, e um garoto então, apresenta o mesmo número de relações diretas que sua mãe (9), e o maior índice de relevância da rede aqui estudada. A relevância de um nó na rede é calculada com base na centralidade dos outros nós com que o primeiro se relaciona. Assim, um nó ou agente adquire relevância quando se relaciona com outros nós bem relacionados dentro da mesma rede. Esse índice elevado,

\footnotetext{
42 WASSERMAN, Stanley; FAUST, Katherine. Social Network Analysis... Op. cit. p. 174-177.

${ }^{43}$ Embora esta prática fosse proibida pelas Constituições Primeiras do Arcebispado da Bahia, em seu título XIII. Ver: DAVIDE, Sebastião M. Constituições Primeiras do Arcebispado da Bahia. Lisboa: Typ. 1719. [São Paulo, 1853]. Disponível em: <http://www2.senado.leg.br/bdsf/item/id/222291>. Acesso em: 5 set. 2016.
} 
quando o mesmo era apenas um adolescente, sugere que o mesmo foi preparado desde cedo para assumir o comando da família, concedendo o seu 'dom' como padrinho já desde jovem. Contudo, cabe destacar que o perfil das relações formadas por Rafael era qualitativamente diferente daqueles que vimos para Clara: entre os compadres com que ele estabeleceu relações nesse período, contamos 6 colonos migrantes (sendo 4 deles açorianos), um negro forro, uma índia e um casal de escravos de seu pai. Além disso, ele batizou também um primo.

Diferente de sua mãe e de suas tias, o perfil do padrinho Rafael esteve majoritariamente voltado para a formação de relações verticais, atendendo a famílias de estratos subalternos que possivelmente concorreram para o apoio de seu grupo familiar na condição de clientes (como peões, capangas e, no caso, um casal de escravos do pai). Essa tendência indica um padrão de ligação vertical que foi mantido nos anos posteriores, quando o já adulto Rafael Pinto Bandeira se tornou um proeminente chefe militar e político da região, conforme identificou o estudo de Tiago Luís Gil "O Bando de Rafael Pinto Bandeira em uma representação gráfica: uma tentativa de aplicação da social network analysis na história social". Gil demonstra que este padrão foi mantido nas décadas seguintes, quando Rafael assumiu a função de "líder de um poderoso 'bando' [...], uma organização de pessoas de diferentes estratos sociais, associadas através de diversos vínculos, especialmente parentais e de reciprocidade". ${ }^{44}$

A manutenção desse padrão de relacionamentos ao longo ao longo dos anos poderia significar, para os envolvidos, acesso às várias formas de contrapartidas oferecidas, ao mesmo tempo que reproduzia "a desigualdade congênita daquela sociedade, possibilitando o acesso de uns ao que a maioria não possuía". ${ }^{45}$ O futuro 'patrão' Rafael, já em sua juventude, portanto, apresentava uma tendência a formar o que denominamos relações verticais diretas, o que poderia já neste período identificar uma estratégia de atuação familiar de vincular os integrantes de uma base social diversa ao jovem que estava sendo preparado para assumir a liderança do grupo.

Entrementes, a atuação dos filhos parece ter sido importante para o estabelecimento das relações da casa de Francisco Pinto Bandeira, tendo em vista que em quatro ocasiões a jovem Desidéria, filha do casal, esteve ao lado do irmão Rafael nas cerimônias batismais. A diferença, aí, parece estar na seleção dos afilhados, que parece ter sido mais criteriosa para a filha: sua 'graça' foi concedida apenas a filhos de pais livres, sobretudo casais de colonos açorianos residentes nas terras do pai. Este fato reforça a importância dos filhos do casal na formação de relações verticais com famílias da região, permitindo criar uma noção de continuidade e lealdade entre os clientes vinculados ao Pinto Bandeira.

Autores como João Fragoso indicam a importância desse tipo de relacionamento em sociedades de Antigo Regime, ${ }^{46}$ onde famílias de estratos sociais diferentes de conectavam por compartilharem de interesses complementares: se os colonos e cativos buscavam no padrinho

\footnotetext{
${ }^{44}$ GIL, Tiago Luís. O bando de Rafael... Op. cit., p. 3.

45 Ibidem, p. 4.

${ }^{46}$ FRAGOSO, João. Capitão Manuel Pimenta... Op. cit., p. 249.
} 
a possibilidade de favorecimento ou proteção, a família se beneficiava por ampliar sua base social, reunindo homens que poderiam ser acionados para defender seus interesses, ou mãode-obra para trabalhar em seus negócios. Em todo caso, é sugestivo que a tarefa de construir essas relações recaia, principalmente, sobre o filho mais velho, que formou uma rede pessoal que abarcava este substrato, ao mesmo tempo que o conectava a outros senhores de terras e familiares.

A percepção da importância das relações verticais para a manutenção dos status social dessa família sulista encontra correspondência, na literatura, em estudos que analisaram outras regiões do Brasil colonial, como nos caso das Minas Gerais. Conforme aponta Andrade, a maneira como estavam relacionados livres, libertos e escravos demonstrava a existência de uma estratificação social complexa, onde o enraizamento e a distinção social, em diversas ocasiões, guiavam as escolhas realizadas na pia batismal, delimitando o lugar social dos indivíduos e reiterando as hierarquias existentes. ${ }^{47}$ Por outro lado, conforme Genovez, a reiteração dos vínculos relacionais intraelites concorria para reforçar posições de amizade e privilégio, contribuindo para a obtenção de terras e títulos pelos membros da elite colonial. ${ }^{48}$

Outro grupo importante durante a formação da freguesia se organizou em torno do conhecido Porto do Dorneles, sob a liderança do sesmeiro Jerônimo de Ornellas de Menezes e Vasconcellos, que se estabeleceu no Morro de Sant'Anna por volta do ano de 1740. Natural do arquipélago da Madeira, Jerônimo de Ornellas é apontado em outros trabalhos e nas genealogias disponíveis como descendente da fidalguia insular, e migrou para o Continente na década de 1730. Antes disso, havia se casado em Guaratinguetá com Lucrécia Leme Barbosa, filha de uma das "melhores famílias" locais e também descendente dessa fidalguia, ${ }^{49}$ sendo por sua vez também prima em terceiro grau do capitão-mor Francisco Brito Peixoto, já mencionado aqui.

A região do então 'Porto do Dorneles', dentro das terras de Jerônimo, anos mais tarde serviria como base para o núcleo urbano inicial da atual capital gaúcha, Porto Alegre, enquanto a localidade onde se situava seu fogo corresponde à região de divisa entre os atuais municípios de Porto Alegre e Viamão, o Morro de Sant'Anna. Além deste núcleo, se ligavam a esta família por laços de parentesco e matrimônio outros proprietários locais. O português Dionísio Rodrigues Mendes, por exemplo, casou-se com a irmã de Lucrécia Leme Barbosa, Dona Beatriz Barbosa Rangel, e era portanto concunhado de Jerônimo, sendo também considerado um dos precursores da povoação viamonense. Finalmente, havia também o paulista Francisco Xavier de Azambuja, também oriundo de família potentada e ocupante da sesmaria vizinha a de Jerônimo de Ornellas, tendo sido casado com sua filha Rita de Menezes. Como se vê, este

\footnotetext{
47 ANDRADE, Mateus Rezende. Da senzala à capela. Compadrio, redes sociais e algumas considerações sobre o lugar social de "pardos livres" nas Minas Gerais oitocentistas. Revista Brasileira de História \& Ciências Sociais - RBHCS, São Leopoldo, v. 7, n. 14, 78-99, 2015. Disponível em: <https://www.rbhcs.com/rbhcs/article/view/291>. Acesso em: 21 maio 2018.

48 GENOVEZ, Patrícia Falco. Barões numa perspectiva reticular: análise de redes sociais, poder e nobreza na Zona da Mata Mineira no segundo Reinado. Tempo, Rio de Janeiro, v. 16, n.30, 243-266, 2011. Disponível em: <http://www.redalyc.org/articulo.oa?id=16701848101>. Acesso em: 21 maio 2018.

${ }^{49}$ KUHN, Fabio. Gente da Fronteira... Op. cit., p. 217.
} 
grupo possuía fortes raízes em famílias da fidalguia, e isso se refletiu na extensa rede constituída por seus membros no Continente.

A família Ornellas aparece em 44 registros de batismo do 10 livro de batismos. A rede construída a partir destes registros conta com 94 agentes, incluindo o patriarca, sua esposa, 9 filhos e filhas e cinco genros e noras. No período compreendido por este ensaio, 12 netos de Jerônimo de Ornellas foram batizados, enquanto seus familiares atuaram como padrinhos de 36 crianças nascidas em outras famílias. A rede de compadrios da família Ornellas, a exemplo da analisada anteriormente, também conta com a participação de agentes de estratos sociais diversificados, havendo inclusive um registro de batismo de uma criança exposta. Esta rede está representada no Grafo 2, abaixo

O componente visual traz uma contribuição valiosa para o entendimento da dinâmica de funcionamento das relações entre àquelas pessoas, especialmente ao permitir enxergar a importância que alguns agentes assumiam ao estabelecer um número maior de relações (os laços ou linhas da rede), por um lado, ou o papel desempenhado pelos atores que conectam diferentes grupos dentro da mesma rede (intermediários) por outro. Para exemplificar, vamos analisar o papel de alguns membros da família a partir desta representação visual.

Grafo 2: Rede de compadrio da Família Ornellas de Menezes, 1747-1759

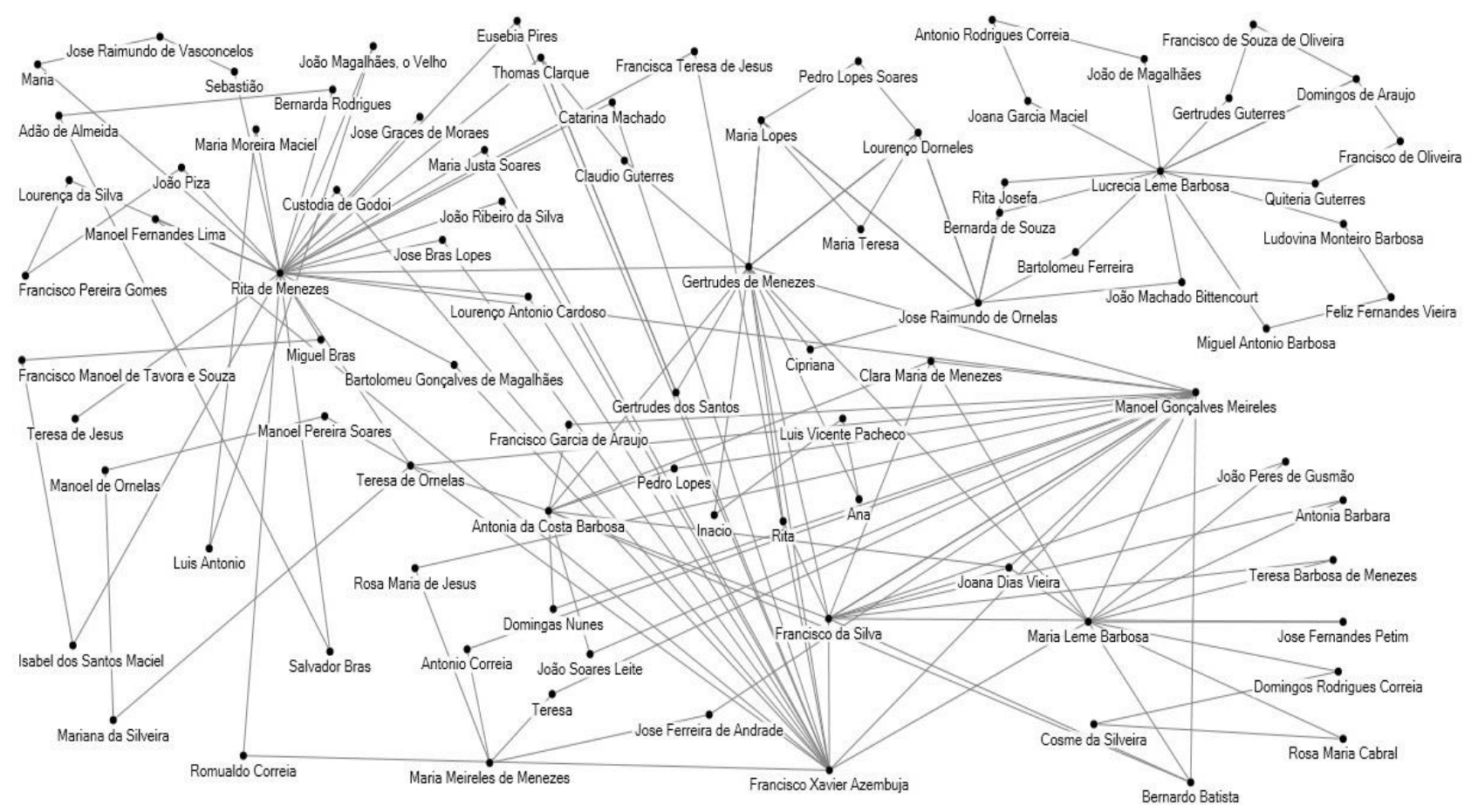

Fonte: Livro 10 de Batismos de Viamão - 1747-1759. 
O primeiro elemento que nos chama atenção é a concentração de laços em torno de alguns dos agentes que compunham esta rede, ou seja, a elevada centralidade de alguns agentes. Os três nomes que concentram o maior número de relacionamentos são os de Rita de Menezes, filha de Jerônimo de Ornellas, e os genros Francisco Azambuja (esposo de Rita) e Manoel Meireles; mas também se destacam outras filhas, como Gertrudes e Maria, além da esposa de Jerônimo, Lucrécia. Por outro lado, notamos que alguns nós cumprem o papel de ligar diferentes grupos de maior densidade dentro da rede: estes são os casos dos irmãos Teresa, Clara e José Raimundo.

Interessante notar, também, como o casal Francisco Azambuja e Rita Menezes concentra um alto número de relações, normalmente partilhadas com outros familiares, enquanto outros membros da rede formam subgrupos periféricos. Ao que parece, o casal Francisco e Rita estava bastante integrado às estratégias de atuação familiar, aparecendo nos róis de confessado de Viamão como residentes no fogo vizinho ao de pai de Rita. Essa trama densa em torno do casal os coloca (especialmente à Rita) na posição que Sílvia Brügger e Luís Farinatti chamam de "campeões de batismo", ${ }^{50}$ pessoas procuradas de forma recorrente para atuar como padrinhos e madrinhas dentro de suas comunidades.

Para compreender melhor os papéis de cada um, vejamos, então, as métricas individuais de alguns dos membros da família:

Tabela 2: Métricas da rede de compadrio da família Ornellas de Menezes

\begin{tabular}{|l|c|c|c|c|}
\hline & Centralidade & $\begin{array}{c}\text { Coeficiente de } \\
\text { Intermediação }\end{array}$ & $\begin{array}{c}\text { Grau de } \\
\text { Proximidade }\end{array}$ & $\begin{array}{c}\text { Grau de } \\
\text { Relevância }\end{array}$ \\
\hline Rita de Menezes & 27 & 1620,79 & 0,005 & 0,059 \\
\hline Manoel Gonçalves Meireles & 17 & 863,226 & 0,004 & 0,061 \\
\hline Francisco Xavier Azambuja & 17 & 473,205 & 0,004 & 0,057 \\
\hline Gertrudes de Menezes & 14 & 1814,507 & 0,005 & 0,05 \\
\hline Maria Leme Barbosa & 12 & 431,983 & 0,004 & 0,041 \\
\hline Francisco da Silva & 12 & 216,874 & 0,004 & 0,046 \\
\hline Lucrecia Leme Barbosa & 11 & 871,333 & 0,002 & 0 \\
\hline Antonia da Costa Barbosa & 10 & 143,093 & 0,004 & 0,034 \\
\hline Jose Raimundo de Ornelas & 7 & 1125,25 & 0,003 & 0,003 \\
\hline Teresa de Ornelas & 6 & 265,319 & 0,004 & 0,03 \\
\hline Jerônimo de Ornellas & 2 & 1 & 0,5 & 0 \\
\hline
\end{tabular}

Fonte: Livro $1^{\circ}$ de Batismos de Viamão, 1747-1759.

\footnotetext{
${ }^{50}$ BRUGger, Silvia M. J. Minas Patriarcal... Op. cit.; FARINATTI, Luís A. E.; VARGAS, Jonas Moreira. Elites regionais, guerra... Op. Cit., p. 389-413.
} 
Como já apontado, destaca-se a centralidade dos agentes mais relacionados. Rita de Menezes, por exemplo, concentra 27 vínculos no período (lembremos que na rede anterior esse índice chegou a no máximo 9). Considerando os 17 vínculos de seu esposo, Francisco (alguns deles compartilhados), podemos afirmar que este casal era extremamente bem relacionado naquele momento. Entre seus compadres, aparecem proprietários, colonos, um padre e também um casal de escravos, além de irmãos(ãs) e cunhados(as). Em contraponto, o patriarca da família, Jerônimo, tem uma participação discreta nessa rede, batizando apenas uma criança. Já Gertrudes Magna de Menezes, outra das filhas de Jerônimo, aparece como uma das pessoas que apresenta o conjunto de relações mais diversificado, ao incluir entre suas comadres três mulheres escravas, além de um compadre forro.

Esta, aliás, é uma característica que chama atenção nesta rede. Apesar da predominância das relações entre livres, a participação do substrato cativo é mais evidente nas relações deste grupo. As filhas de Jerônimo de Ornellas atuam com frequência no estabelecimento de relações sociais verticais, comparecendo como comadres de dez negros cativos (três homens e sete mulheres), além de dois negros forros. Entre os proprietários destes cativos, constam fazendeiros como Francisco de Távora e Domingos Ribeiro, além do cunhado Francisco da Silva e o próprio pai, Jerônimo.

João Fragoso aponta que o compadrio entre estratos cativos e livres foi uma das formas de controle adotada por famílias senhoriais no Brasil do período colonial. ${ }^{51}$ Assim, a linguagem do parentesco fictício tornava-se uma das maneiras de se estabelecer pactos entre senhores e seus escravos, estabelecendo assim compromissos de lealdade e proteção, de cliente e patrão. Nessa relação hierarquizada, baseada em noções de disciplina e reciprocidade, não eram apenas os senhores que saíam ganhando: reproduzindo no interior dos plantéis a estrutura estratificada que atravessava aquela sociedade, os escravos que figuravam no polo 'passivo' destas relações criavam expectativas de se diferenciarem socialmente, o que poderia ocorrer, por exemplo, através da permissão para cultivar sua própria terra, acessar tarefas especializadas e, quem sabe, alcançar sua alforria.

Uma das características que diferenciavam estes cativos dos demais dentro dos plantéis era a adoção de sobrenomes ou apelidos, geralmente aqueles das famílias às quais pertenciam. Fragoso aponta que essa não era uma relação gratuita nem generalizada, mas obedecia a estratégias de parte a parte que concorriam para os objetivos de diferenciação e legitimidade buscados. No caso dos registros analisados aqui, esses escravos não apresentavam apelidos nem outros signos que indicassem uma distinção em relação aos seus colegas de cativeiro; se bem que essa diferenciação poderia estar expressa no próprio laço ritual estabelecido com seus compadres.

Voltando as relações da família Ornellas, se observarmos a última coluna da tabela, por outro lado, veremos que a matriarca Lucrécia Barbosa aparece com grau de relevância 0 (assim como seu esposo). Isso pode causar certo estranhamento, a princípio, por isso

${ }^{51}$ FRAGOSO, João. Capitão Manuel Pimenta... Op. cit., p. 260. 
precisamos observar esse dado com mais cuidado. Já apontamos que a relevância de um nó em uma rede corresponde ao número de relacionamentos deste com outros nós bem relacionados. No caso de Lucrécia, podemos observar no Grafo 2 que esta não apadrinhou nenhum de seus netos, e por isso não se relaciona diretamente com nenhum outro membro da família. Por outro lado, o grafo demonstra que Lucrécia concentrou em torno de si um número razoável de ligações, estabelecendo ao redor de si um subgrupo composto de outras 15 pessoas. Por isso, ela possui um grau de intermediação elevado: essas pessoas, proprietários e colonos que com ela estabeleceram uma relação de parentesco ritual, tinham Lucrécia como a única intermediária junto ao seu grupo familiar. Seus filhos Rita, Manoel, Gertrudes e José também aparecem como intermediários importantes dentro da rede.

A apresentação da rede dos Ornellas torna oportuno abordar outras medidas que podemos produzir a partir da SNA. Temos trabalhado, até aqui, com métricas individuais produzidas para os agentes da rede. Mas a SNA nos permite, também, gerar métricas para a rede em si, contribuindo para a compreensão do funcionamento do grupo e de sua dinâmica interna. Neste ensaio nos ocuparemos de duas delas.

Primeiramente, temos o conceito de densidade, que corresponde à relação entre o número de laços (relações) existentes em uma rede e o número de laços virtualmente possíveis, onde 1 representa a densidade máxima que uma rede pode alcançar, e 0 corresponde a uma rede (ou um fragmento de rede) sem nenhum relacionamento identificado. Para exemplificar, tomemos uma rede qualquer formada por quatro pessoas, A, B, C e D. Em uma representação multidirecional dessa rede, o número de vínculos possíveis seria 6 . Agora, supondo que estes 4 atores estabelecem entre si 4 relacionamentos, a densidade da rede formada seria calculada pela razão entre 6 e 4, resultando em um índice de densidade de 0,67.

Outra métrica que nos interessa aqui é a distância geodésica. A distância geodésica entre dois pontos da rede é simplesmente o número de laços que separam dois atores, considerando o caminho mais curto. Tomemos dois exemplos da segunda rede apresentada: nela, os cunhados Francisco Azambuja e Maria Leme Barbosa se conectam diretamente, assim a distância geodésica entre eles é 1 . Por outro lado, o forro Inácio, que teve uma filha batizada por Gertrudes de Menezes, não se relaciona diretamente com o patriarca da família, por exemplo. Uma relação fictícia entre estes dois agentes seria mediada (considerando aqui os relacionamentos de compadrio) por outras cinco pessoas, o que significa uma distância geodésica de grau 6. Essa métrica é particularmente interessante para refletir a respeito dos conceitos de estratégia e intermediação dentro de uma rede determinada. Chamamos de distância geodésica máxima, ou diâmetro, o caminho mais longo que separa dois agentes dentro de uma rede, um conceito que pode nos fornecer uma ideia da extensão da rede e do número de subgrupos que se organizam dentro da mesma.

Considerando estas duas métricas para as redes apresentadas, podemos tentar estabelecer uma rápida comparação a respeito de suas características. A rede dos Pinto Bandeira apresenta densidade de grau 0,02 e diâmetro 9. Por sua vez, a rede da família Ornellas apresenta densidade de 0,04 e diâmetro 10. Considerando estas duas estatísticas, 
podemos deduzir que estas redes apresentam algumas semelhanças. Ambas as redes apresentam grau de densidade baixos; porém, possuem atores que apresentam alto índice de centralidade. Isso nos leva a um diâmetro próximo para ambas as redes, implicando em redes que eram constituídas por subgrupos com associações mais densas, normalmente organizados em torno de agentes importantes, e que eram ligados por pessoas que faziam a intermediação entre estes (normalmente filhos e filhas que concentravam um número menor de ligações, mas conectavam grupos distintos dentro da rede).

As duas redes também demonstram que as mulheres eram amplamente incorporadas às estratégias familiares, cumprindo papéis importantes, ao menos quando consideramos as relações de compadrio. Em ambos os casos, os chefes de família não exerceram o papel de padrinhos com frequência, sendo as relações de parentescos espiritual das famílias mediadas pelos filhos e esposas. Donald Ramos, em seu estudo sobre as instituições do batismo e do compadrio para a região das Minas Gerais no século XVIII, ${ }^{52}$ já apontava para a importância da mulheres na construção das relações reticulares através do parentesco espiritual, especialmente como mecanismo de reforço de relações intrafamiliares. Essa característica fica evidenciada para as redes identificadas a partir dos registros de batismo de Viamão, considerando a importância que as 'donas' cumpriam. Essas mulheres, esposas e filhas dos potentados da terra, frequentemente aparecem como madrinhas preferenciais da freguesia, concedendo seu dom à crianças de estratos diversificados e contribuindo, assim, para a ampliação da clientela de suas famílias.

Por outro lado, destaca-se a importância cumprida pelos filhos e filhas destas famílias potentadas: enquanto o jovem Rafael se destaca na rede dos Pinto Bandeira, as filhas e filhos da família Ornellas (nesse caso já adultos, em sua maioria) também estabelecem uma trama densa de relacionamentos dentro do grupo que orbita seu núcleo familiar. Quando contrapomos essa informação a uma presença mais discreta de seus pais junto à pia batismal, podemos concluir que, enquanto parte de uma estratégia de atuação social, a tarefa de oferecer o dom espiritual em nome da família ficava predominante a cargo de seus rebentos, enquanto os patriarcas Francisco e Jerônimo possivelmente se ocupavam de outras tarefas, tais como a liderança militar do grupo e sua articulação política.

\section{Considerações Finais}

Conforme aponta João Fragoso, a sociedade constituída no Brasil do período colonial era marcada por uma "hierarquia social costumeira, construída pela interação de potentados, escravos, forros, índios, ministros da Coroa, clérigos, etc.", onde as relações sociais entre esses grupos se traduzia em uma sociedade altamente hierarquizada e interdependente, como

52 RAMOS, Donald. Teias sagradas e... Op. cit. 
indicamos anteriormente. ${ }^{53}$ Essa ideia de interdependência é central para entender a convivência desses distintos estratos sociais em redes do período setecentistas: senhores, peões, migrantes, escravos e forros encontravam-se todos imbricados em uma complexa teia de relacionamentos, que se constituía na própria base de sustentação dessa sociedade, compartilhando recursos e vivências dentro de uma dinâmica sociocultural que interligava essas pessoas. É esse tipo de peculiaridade, a nosso ver, que pode ser demonstrado de forma privilegiada pela análise destas redes de apadrinhamento, colocando em evidência as formas como se construíam e se hierarquizavam essas relações, permitindo ao historiador interrogarIhes novos sentidos.

No presente texto buscamos produzir um breve ensaio, utilizando as ferramentas fornecidas pela Análise de Redes Sociais para examinar algumas das características das redes de apadrinhamento formada pelas famílias Pinto Bandeira e Ornellas de Menezes em meados do século XVIII, com o objetivo de tecer algumas considerações iniciais a respeito da forma como a instituição do compadrio era utilizada por estas famílias latifundiárias. Considerando o referencial adotado e nossos resultados preliminares, as relações identificadas sugerem o uso do compadrio como parte de uma estratégia social dessas famílias. As redes apresentadas permitem identificar um conjunto de alianças verticais e horizontais, onde temos, por um lado, ligações entre famílias de proprietários rurais, que se ligavam através do parentesco ritual ao batizar os filhos uns dos outros, enquanto a associação com outras camadas sociais indica a utilização do compadrio também para o fortalecimento das relações verticais destas famílias com estratos subalternos dessa sociedade, que Ihe serviam de base social e política.

Em relação à rede da família Pinto Bandeira, os elevados coeficientes de agrupamento e intermediação registrados para as esposas de Francisco (Clara) e José (Bernarda) demonstram que as mesmas cumpriam papel importante na construção das relações sociais da família. Por outro lado, o alto grau de relevância de Rafael Pinto Bandeira nesta rede, quando o mesmo era apenas um adolescente, sugere que o mesmo já nesta época estava sendo integrado às estratégias de atuação familiar, como filho primogênito do casal Francisco e Clara.

Algumas das características dessa rede são reforçadas pela análise das relações estabelecidas pela família Ornellas, onde os filhos e, especialmente, as filhas, cumprem papel importante na construção de relações rituais do seu grupo familiar. Somando a isso às métricas calculadas para cada grupo, que se mostraram semelhantes, podemos pensar que estas famílias proprietárias lançavam mão de estratégias semelhantes em sua ação junto à comunidade onde se inseriam.

A imagem que nos vem à mente a partir do estudo dessas relações é a de teias superpostas no tempo e no espaço, integrando personagens de diferentes estratos sociais em intrincadas redes de proteção, favorecimento e reciprocidade. Assim, ao analisar as redes formadas através da instituição do compadrio por potentados da terra, o que percebemos foi uma presença regular de indivíduos provenientes dos estratos econômicos inferiores daquela

${ }^{53}$ FRAGOSO, João. Capitão Manuel Pimenta... Op. cit., p. 249. 
sociedade, surgindo como compadres-clientes que ofereciam seus rebentos como afilhados e personificavam as normas de hierarquia e equidade que atravessavam àquela sociedade. Assim, conforme Fragosoe outros autores já demonstraram, ${ }^{54}$ surgem as figuras dos senhores 'compadres de pretos', de colonos, de padres, de governadores, de outros senhores; o esqueleto semirrígido daquela sociedade se vê transpassado por linhas imaginárias que, ao mesmo tempo, conectavam os diversos pontos da rede e mantinham cada um em seu lugar.

${ }^{54}$ FRAGOSO, João. Capitão Manuel Pimenta... Op. cit. 